УДК 796.853.23:796.012.2

DOI https://doi.org/10.26661/2663-5925-2020-1-14

\title{
СПЕЦИФІКА РОЗВИТКУ КООРДИНАЦІЙНИХ ЗДІБНОСТЕЙ У ДЗЮДОЇСТІВ НА ЕТАПІ СПЕЦІАЛІЗОВАНОЇ БАЗОВОЇ ПІДГОТОВКИ
}

\author{
Кокарев Б. В. \\ кандидат наук з фізичного виховання і спорту, \\ дочент кафедри фізичної культури і спорту \\ Запорізький наиіональний університет \\ вул. Жуковського, 66, Запоріжжя, Україна \\ orcid.org/0000-0002-2335-6611 \\ kokarevb@gmail.com
}

Кокарева С. М.

старший викладач кафедри фізичної культури, олімпійських та неолімпійських видів спорту

Національний університет «Запорізька політехніка»

вул. Жуковського, 64, Запоріжжя, Україна

orcid.org/0000-0002-3435-4929

kokarevas@gmail.com

\section{Щербій С. А.}

старший викладач кафедри фізичної культури, олімпійських та неолімпійських видів спорту Національний університет «Запорізька політехніка»

вул. Жуковського, 64, Запоріжжя, Україна

orcid.org/0000-0002-7740-3006

sergey.scherbiy@gmail.com

\section{Данильченко С. I.}

старший викладач кафедри фізичної культури, олімпійських та неолімпійських видів спорту

Національний університет «Запорізька політехніка»

вул. Жуковського, 64, Запоріжжя, Україна

orcid.org/0000-0001-7557-092X

svyat.danilchenko@gmail.com

Ключові слова: дзюдо, динаміка, засоби, навички, вдосконалення.
У зв'язку зі зниженням в останніх олімпійських циклах досягнень українських спортсменів на світовій спортивній арені відбувається активний пошук ефективних шляхів удосконалення різних сторін підготовленості спортсменів. Зокрема, не втрачає актуальності розробка адекватних методик розвитку координаційних здібностей.

Мета дослідження - розробити та експериментально обгрунтувати методику вдосконалення навчально-тренувального процесу, спрямованого на розвиток координаційних здібностей у дзюдоїстів.

Методи дослідження: педагогічні спостереження; опитування, педагогічний експеримент; контрольні випробування; експертна оцінка; математична статистика.

Результати роботи. 3'ясовано, що навчально-тренувальний процес на етапі спеціалізованої базової підготовки здебільшого спрямований на зміцнення здоров'я, поліпшення фізичного розвитку, оволодіння основами техніки виконання фізичних вправ, надбання різнобічної фізичної 
підготовленості, виявлення задатків і здібностей, прищеплення стійкого інтересу до занять дзюдо. Основне завдання етапу - залучення максимально можливої кількості дітей і підлітків до систематичних занять.

Вихідні показники розвитку координаційних здібностей у дзюдоїстів контрольної та експериментальної груп перебували на одному рівні, відмінності недостовірні. Наприкінці експерименту констатували виражене покращення результатів експериментальної групи, яке було набагато більшим за всіма пунктами порівняно із контрольною. Таким чином, отримані дані переконливо свідчать про високу ефективність експериментальної методики, спрямованої на розвиток координаційних здібностей.

Ключові висновки. Під час дослідження визначено динаміку вдосконалення координаційних здібностей і встановлено іiі позитивний характер в усіх учасників експерименту. Підтверджено раніше зроблені висновки про ефективність цілеспрямованого впливу на показники координаційних здібностей у дзюдоїстів, які займаються в групах спеціалізованої базової підготовки. Доповнено дані щодо основних засобів розвитку координаційних здібностей єдиноборців.

\title{
SPECIFICS OF DEVELOPMENT OF COORDINATION ABILITIES FOR JUDOISTS AT THE STAGE OF SPECIALIZED BASIC TRAINING
}

\author{
Kokarev B. V. \\ Candidate of Science in Physical Education and Sports, \\ Associate Professor at the Department of Physical Culture and Sports \\ Zaporizhzhia National University \\ Zhukovsky str., 66, Zaporizhzhia, Ukraine \\ orcid.org/0000-0002-2335-6611 \\ kokarevb@gmail.com
}

Kokareva S. M.

Senior Lecturer at the Department of Physical Culture, Olympic and Non-Olympic Sports

National University "Zaporizhia Polytechnic"

Zhukovsky str., 64, Zaporizhzhia, Ukraine

orcid.org/0000-0002-3435-4929

kokarevas@gmail.com

Sherbiy S. A.

Senior Lecturer at the Department of Physical Culture, Olympic and Non-Olympic Sports

National University "Zaporizhia Polytechnic"

Zhukovsky str., 64, Zaporizhzhia, Ukraine

orcid.org/0000-0002-7740-3006

sergey.scherbiy@gmail.com

Danilchenko S. I.

Senior Lecturer at the Department of Physical Culture, Olympic and Non-Olympic Sports

National University "Zaporizhia Polytechnic"

Zhukovsky str., 64, Zaporizhzhia, Ukraine

orcid.org/0000-0001-7557-092X

svyat.danilchenko@gmail.com 
Key words: judo, dynamics, resources, and skills improvement.
Due to the decline in the last Olympic cycles of achievements of Ukrainian athletes on the world sports arena, there is an active search for effective ways to improve various aspects of athletes' fitness. In particular, the development of adequate methods for developing coordination abilities remains relevant. Purpose of research. To develop and experimentally validate a methodology for the improvement of the training process aimed at the development of coordination abilities in judo.

Research methods: pedagogical observations; survey, pedagogical experiment; control tests; expert assessment; mathematical statistics.

Result of work. It was found out that the training process at the stage of specialized basic training is mainly aimed at improving health, improving physical development, mastering the basics of physical exercise techniques, acquiring versatile physical fitness, identifying the makings and abilities, instilling a strong interest in judo. The main task of the stage is to attract the maximum possible number of children and adolescents to systematic classes.

The initial indicators of development of coordination abilities in judoists of the control and experimental groups were at the same level, the differences are unreliable. At the end of the experiment, there was a marked improvement in the results of the experimental group, which was much greater in all points compared to the control group. Thus, the obtained data strongly indicate the high efficiency of the experimental technique aimed at developing coordination abilities.

Key finding. In the course of the study, the dynamics of improving coordination abilities was determined and its positive character was established in all participants of the experiment. Previously made conclusions about the effectiveness of targeted influence on indicators of coordination abilities of judoists engaged in groups of specialized basic training are confirmed. Data on the main means of development of coordination abilities of single combats are supplemented.
Постановка проблеми. Загальновідомо, що на етапах початкової підготовки закладаються основи подальшого зростання спортивної майстерності майбутнього атлета. Боротьба не стоїть осторонь від інших видів спорту. Вона стає більш агресивною та темповою, що висуває підвищені вимоги до різних сторін підготовки спортсменів. В останне десятиліття істотно змінилися методичні підходи до вдосконалення їх технічної та тактичної майстерності, підвищення рівня розвитку фізичних і покращення психічних якостей спортсменів [2, с. $5-6 ; 4$, с. $10 ; 12$, с. 296].

Існує обгрунтована думка, що основу підготовки спортсмена-єдиноборця становить розвиток координаційних здібностей. Адже саме за допомогою складних за координаційною структурою рухів вирішуються завдання змагальної діяльності. Аналіз вітчизняної та зарубіжної науково-методичної літератури показує, що нині існують різні погляди на розвиток координаційних здібностей у процесі спортивної підготовки.

Так, одні автори пропонують здійснювати розвиток інтегровано під час реалізації процесу технічної підготовки, інші - розглядати місце координаційного тренування крізь призму розвитку координаційних здібностей у системі фізичної підготовки. Треті переконані в необхідності виділення координаційної підготовки в якості самостійного та найважливішого розділу підготовки спортсмена, якому притаманні певні завдання, засоби і методи розвитку координаційних здібностей у тому чи іншому виді спорту $[5$, c. $18 ; 7$, с. $18 ; 10$, c. 6$]$.

У роботах більшості авторів вказується на явне протиріччя, яке існує в сучасній практиці підготовки спортивного резерву в єдиноборствах. Воно полягає в тому, що на початковому етапі підготовки спортсменів у дитячих спортивних школах здебільшого переважає ОФП.

Тут можна звернути увагу на два аспекти проблеми. По-перше, в будь-якому виді спортивної боротьби на змаганнях оцінюються виключно специфічні технічні дії (прийоми), які дають підстави до присудження перемоги в поєдинку того чи іншого спортсмена. По-друге, діти, які прийшли освоювати певний стиль боротьби, через засилля непомірних фізичних навантажень і небажання орієнтуватися на відставлений ефект від занять на початковому етапі завчасно залишають спортивні секції [1, с. 35-36: 3, с. 1-2; 8, с. 2].

Очевидно, що в сучасній практиці початкової підготовки в спортивних єдиноборствах існує 
проблема між співвідношенням пропонованого програмним матеріалом обсягом засобів тренування і місцем координаційної підготовки юних спортсменів у них.

Робота $є$ частиною наукових програм факультету фізичного виховання, здоров'я та туризму кафедри фізичної культури і спорту Запорізького національного університету. Вона виконана в рамках теми «Сучасні технології підготовки спортсменів різної спеціалізації і кваліфікації в олімпійських видах спорту» (номер державної реєстрації 0116U004848).

Аналіз останніх досліджень i публікацій. Питання підбору засобів тренування для розвитку координаційних здібностей у спортивних видах єдиноборств вивчалися багатьма фахівцями [5, с. $19-20: 6$, с. $74 ; 7$, с. 176 ; 9, с. 213].

Дослідження, проведені за останні 10 років, довели, що поєдинки дзюдоїстів характеризуються високою інтенсивністю техніко-тактичних дій, які вимагають від спортсменів високих координаційних здібностей, вміння швидко виявляти зміни в тактичній обстановці. Під час спортивного поєдинку атакуючі та захисні дії можуть бути використані в різних комбінаціях і послідовності, тому саме єдиноборства вимагають вияву координаційних здібностей $[3$, с. $2 ; 8$, с. $1 ; 13$, с. 2 ; 14 , c. $147-148]$.

У попередніх дослідженнях було встановлено, що координація рухів піддається найбільшому впливу саме протягом тривалості етапу попередньої базової підготовки. Також встановлено, що взаємозв'язку між рівнем фізичного розвитку дітей і рівнем розвитку координаційних здібностей не існує, тому варто займатися вправами, спрямованими на розвиток координації рухів саме 3 дітьми 10-11 років, які легко піддаються впливу педагогічного процесу, спеціально спрямованого на її розвиток $[4$, с. $10 ; 5$, с. $20-21 ; 8$, с. 3 ; 15 , c. 253-254].

3'ясовано, що високий ступінь розвитку координації рухів позитивно впливає на оволодіння дітьми новими руховими формами, а координаційні здібності зберігаються протягом тривалого терміну. Однак спрямованість педагогічних впливів тренування при розвитку координаційних здібностей у дзюдоїстів, на наш погляд, потребує подальшого вивчення та доповнення $[5$, с. 22 ; 6 , c. $75 ; 7$, с. $33 ; 11$, с. $5-6]$.

У науковій літературі, насамперед із високими міжнародними індексами цитування, не досить досліджень, присвячених вихованню координаційних здібностей у спортивних єдиноборствах, особливо у дзюдо, в спортсменів молодшого віку. Тому ця проблематика і зумовила актуальність дослідження.
Метою дослідження було розробити та експериментально обгрунтувати методику вдосконалення навчально-тренувального процесу, спрямованого на розвиток координаційних здібностей у дзюдоїстів, які займаються в групах спеціалізованої базової підготовки.

Відповідно до мети дослідження у роботі було поставлено для вирішення такі завдання:

1. Проаналізувати науково-методичну літературу з досліджуваної проблематики.

2. Проаналізувати тестові показники розвитку координаційних здібностей юних дзюдоїстів 10-11 років, які брали участь в експериментальному дослідженні.

3. Розробити та експериментально довести ефективність авторської методики розвитку координаційних здібностей дзюдоїстів на етапі спеціалізованої базової підготовки, яка грунтується на використанні у навчально-тренувальному процесі додаткових блоків спеціально підібраних акробатичних і гімнастичних вправ.

Матеріал і методи дослідження. Дослідження проводилося на базі ПНЗ «КДЮСШ Динамо» м. Запоріжжя та Запорізького національного університету в період з 01.09.2019 по 15.12.2019. Запорізький національний університет і ПНЗ «КДЮСШ Динамо» мають офіційний договір на співпрацю, у тому числі на проведення подібних наукових досліджень під час проходження студентами педагогічної практики та надання науково-методичної та консультативної допомоги школі викладачами кафедри.

У дослідженні взяли участь діти віком 10-11 років, які займаються дзюдо в групах НТГ-1 (2 групи по 15 хлопчиків). Заняття тривалістю 2,5 академічні години проводилися 5 разів на тиждень. Під час проведених співбесід з учасниками контрольних випробувань і їх батьками, опитування тренерів-викладачів спортивної школи «Динамо» із боротьби дзюдо було отримано їх письмову згоду на участь в експериментальному дослідженні та використання даних анкет і протоколів.

Дослідження здійснювалося в 3 етапи. На першому етапі було проведено аналіз науково-методичної літератури 3 досліджуваної проблеми, сформульовано гіпотезу, визначено мету, завдання та методи дослідження; підібрані тести для проведення педагогічного тестування; розроблено методику навчально-тренувального процесу, спрямовану на розвиток координаційних здібностей у дзюдоїстів.

На другому етапі проведено педагогічний експеримент для обгрунтування ефективності впливу методики на показники координаційних здібностей юних дзюдоїстів. Особливістю проведення навчально-тренувального процесу в експеримен- 
тальній групі було застосування методики, спрямованої на розвиток координаційних здібностей, яка містить спеціалізовано підібрані блоки гімнастичних та акробатичних вправ для розвитку цих здібностей у дзюдоїстів. Заняття проводилися під керівництвом Президента федерації гімнастики Запорізької області, Заслуженого тренера України Б.В. Кокарева. По завершенні етапу було проведено підсумкове тестування і порівняння даних.

На третьому етапі було проведено математико-статистичну обробку даних, аналіз отриманих результатів і сформульовано висновки.

Для реалізації поставленої мети і завдань, для підтвердження гіпотези під час дослідження використовувалися такі методи дослідження: аналіз та узагальнення даних джерел літератури; метод опитування; метод контрольних випробувань; педагогічний експеримент; метод експертної оцінки; методи математичної статистики.

Результати дослідження. За допомогою опитування провідних фахівців Запорізької тренерської школи дзюдо на першому етапі експериментального дослідження було виявлено, що на етапі спеціалізованої базової підготовки пріоритетними для тренерів $\epsilon$ виховна та фізкультурно-оздоровча робота, спрямована на різнобічну фізичну підготовку та оволодіння основами техніки і тактики дзюдо, ставляться завдання залучення максимально можливої кількості дітей і підлітків до систематичних занять дзюдо (рис. 1).

Шляхом виставлення пріоритетних рангів для визначення переважної спрямованості навчально-тренувального процесу в групах спеціалізованої базової підготовки юних дзюдоїстів з'ясовано, що такими насамперед $\epsilon$ зміцнення здоров'я, поліпшення фізичного розвитку $(32,6 \%)$; ово- лодіння основами техніки виконання фізичних вправ $(24,5 \%)$; виявлення задатків і здібностей дітей $(22,4 \%)$; виховання рис спортивного характеру $(7,5 \%)$; прищеплення стійкого інтересу до занять дзюдо (6,7\%), надбання різнобічної фізичної підготовленості на основі різнобічних занять $(6,3 \%)$.

На початку та наприкінці педагогічного експерименту у випробовуваних контрольної та експериментальної груп дзюдоїстів проводилося педагогічне тестування для визначення показників координаційних здібностей.

Розглядаючи вихідні показники координаційних здібностей у дзюдоїстів контрольної та експериментальної груп, можна сказати, що вони перебувають практично на одному рівні, відмінності недостовірні ( $\mathrm{p}>0,05$, табл. 1$)$.

Так, на початку дослідження в обох групах були практично однакові результати за всіма показниками тестів, які характеризують розвиток координаційних здібностей піддослідних спортсменів. Тому ми змогли зробити висновок про те, що на початку експерименту обидві групи юних дзюдоїстів були ідентичні за показниками розвитку координаційних здібностей $(p>0,05)$, тобто сформовані за принципом рівності складу виконавців і їх виконавчої майстерності.

Через п'ять місяців експерименту, під час яких одна $з$ груп (експериментальна, ЕГ) займалася за авторською методикою розвитку координаційних здібностей дзюдоїстів, що грунтується на використанні у навчально-тренувальному процесі експериментальної групи додаткових блоків спеціально підібраних акробатичних і гімнастичних вправ, а друга (контрольна, КГ) - за навчальною програмою для дитячо-юнацьких спортивних

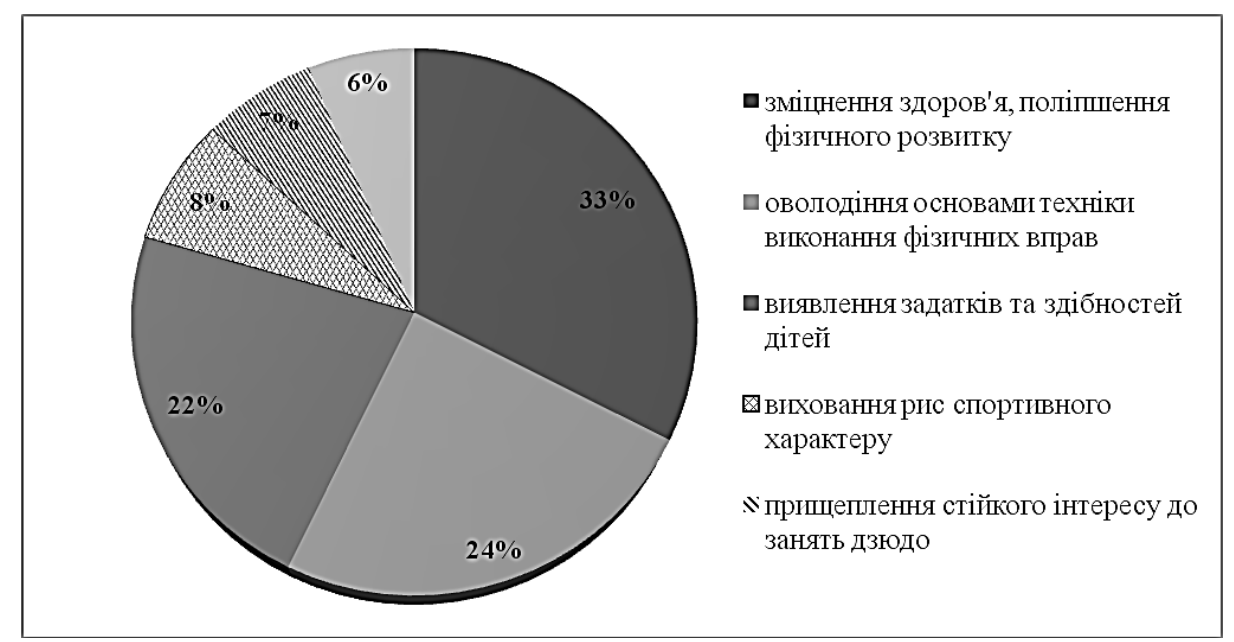

Рис. 1. Пріоритетні ранги переважної спрямованості навчально-тренувального процесу в групах спеціалізованої базової підготовки юних дзюдоїстів 
шкіл [1], було проведено підсумкове тестування координаційних здібностей юних дзюдоїстів. У результаті були отримані відповідні результати (табл. 2).

Так, до кінця педагогічного експерименту відбулося більш виражене зменшення одного з найбільш інформативних показників, а саме коефіцієнту збиваючого впливу в експериментальній групі, що свідчить про більш ефективний розвиток координаційних здібностей у дзюдоїстів експериментальної групи порівняно із контрольною групою.

За рештою показників, якщо на початку дослідження групи відмінності були практично однакові, то наприкінці вони стали відчутнішими. Аналізуючи результати підсумкового тестування, можна зазначити, що приріст показників експериментальної групи виявився набагато більшим за всіма показниками, ніж у контрольній групі.

Відстежуючи результати тестів, наведених у таблиці 2, необхідно зазначити, що порівняно з експериментальною групою контрольна група також підвищила свої показники, але менш значно, ніж ïх опоненти з експериментальної групи. Статистично значущих відмінностей до початку експе- рименту ці зміни не набули ( $>>0,05)$, за виключенням тесту «Стрибок у довжину з місця з вихідного положення обличчям вперед по напрямку руху» $(\mathrm{p}<0,05)$.

Дані таблиці переконливо (за всіма показниками) свідчать, що застосування в експериментальній групі методики, спрямованої на розвиток координаційних здібностей, що включає в себе комплекси спеціалізованих вправ акробатики та гімнастики для розвитку таких здібностей у дзюдоїстів, які займаються в ДЮСШ, в групах спеціалізованої базової підготовки, наприкінці педагогічного експерименту виявило достовірні статистично значущі відмінності в показниках координаційних здібностей між досліджуваними контрольної та експериментальної груп ( $<0,05$, $\mathrm{p}<0,01)$.

Дискусія. Порівнюючи отримані дані опитування 3 даними науково-методичної літератури за темою дослідження, доходимо висновку, що між практичними спеціалістами та науковцями-теоретиками практично немає розбіжностей по суті питання. Так, обидві сторони підкреслюють, що на етапі спеціалізованої базової підготовки періодизація навчально-тренувального процесу носить

Таблиця 1

Достовірність відмінностей у показниках координаційних здібностей у дзюдоїстів на початку педагогічного експерименту, $(\overline{\mathrm{x}} \pm \mathrm{S})$

\begin{tabular}{|l|c|c|c|c|}
\hline \multicolumn{1}{|c|}{ Показники } & KГ (n=15) & $\mathbf{E \Gamma ~ ( n = 1 5 ) ~}$ & $\mathbf{t}$ & $\mathbf{p}$ \\
\hline Три перекиди вперед (сек) & $9,28 \pm 0,14$ & $9,46 \pm 0,19$ & 0,75 & $>0,05$ \\
\hline $\begin{array}{l}\text { Метання тенісного м'яча на точність на відстані } \\
15 \text { метрів правою рукою 3 положення стоячи (разів) }\end{array}$ & $6,10 \pm 0,16$ & $6,20 \pm 0,28$ & 0,64 & $>0,05$ \\
\hline $\begin{array}{l}\text { Метання тенісного м'яча на точність на відстані } \\
15 \text { метрів лівою рукою 3 положення стоячи (разів) }\end{array}$ & $5,29 \pm 0,03$ & $5,36 \pm 0,01$ & 0,53 & $>0,05$ \\
\hline $\begin{array}{l}\text { Стрибок у довжину з місця 3 вихідного положення } \\
\text { обличчям вперед по напрямку руху (см) }\end{array}$ & $141,84 \pm 1,89$ & $141,91 \pm 1,96$ & 0,14 & $>0,05$ \\
\hline $\begin{array}{l}\text { Стрибок у довжину з місця з вихідного положення } \\
\text { спиною вперед по напрямку руху (см) }\end{array}$ & $93,34 \pm 3,13$ & $94,13 \pm 3,19$ & 0,18 & $>0,05$ \\
\hline $\begin{array}{l}\text { Коефіцієнт збиваючого впливу } \\
\text { (умов. од.) }\end{array}$ & 1,33 & 1,31 & 1,68 & $>0,05$ \\
\hline
\end{tabular}

Таблиця 2

Достовірність відмінностей у показниках координаційних здібностей у дзюдоїстів наприкінці педагогічного експерименту, $(\overline{\mathrm{x}} \pm \mathrm{S})$

\begin{tabular}{|l|c|c|c|c|}
\hline \multicolumn{1}{|c|}{ Показники } & $\mathbf{K \Gamma}(\mathbf{n = 1 5})$ & $\mathbf{E} \mathbf{( n = 1 5 )}$ & $\mathbf{t}$ & $\mathbf{p}$ \\
\hline Три перекиди вперед (сек) & $9,13 \pm 0,09$ & $8,81 \pm 0,07$ & 2,91 & $<0,05$ \\
\hline $\begin{array}{l}\text { Метання тенісного м’яча на точність на відстані } \\
\text { 15 метрів правою рукою 3 положення стоячи (раз) }\end{array}$ & $6,51 \pm 0,04$ & $8,36 \pm 0,11$ & 2,89 & $<0,01$ \\
\hline $\begin{array}{l}\text { Метання тенісного м’яча на точність на відстані } \\
\text { 15 метрів лівою рукою 3 положення стоячи (раз) }\end{array}$ & $5,03 \pm 0,05$ & $6,97 \pm 0,04$ & 3,02 & $<0,05$ \\
\hline $\begin{array}{l}\text { Стрибок у довжину з місця з вихідного положення } \\
\text { обличчям вперед по напрямку руху (см) }\end{array}$ & $154,37 \pm 1,84$ & $164,29 \pm 1,92$ & 3,13 & $<0,05$ \\
\hline $\begin{array}{l}\text { Стрибок у довжину з місця 3 вихідного положення } \\
\text { спиною вперед по напрямку руху (см) }\end{array}$ & $96,29 \pm 2,98$ & $109,18 \pm 3,15$ & 2,97 & $<0,05$ \\
\hline $\begin{array}{l}\text { Коефіціснт збиваючого впливу } \\
\text { (умов. од.) }\end{array}$ & 1,29 & 1,23 & 2,07 & $<0,05$ \\
\hline
\end{tabular}


умовний характер, основна увага приділяється різнобічній фізичній і функціональній підготовці 3 використанням насамперед засобів загальної фізичної підготовки, освоєнню технічних елементів і формуванню навичок.

Крім того, підтверджено тезу про те, що сучасний рівень розвитку спорту висуває підвищені вимоги до якості підготовки дзюдоїстів на різних етапах багаторічного навчально-тренувального процесу. Спортивний результат багато в чому детермінується рівнем спеціальної фізичної підготовленості спортсменів.

Особлива роль у спеціальній фізичній підготовці дзюдоїстів відводиться формуванню у них координаційних здібностей. Поєдинки дзюдоїстів характеризуються високою інтенсивністю техніко-тактичних дій, які вимагають від спортсменів високих координаційних здібностей, вміння виявляти їх за швидкої зміни в обстановці.

Все перераховане вище дозволило зробити такі висновки:

1. На основі опитування та аналізу науково-методичної літератури виявлено, що дзюдо складний ситуаційний вид єдиноборства, в якому зустрічається безліч найрізноманітніших положень і рухів спортсменів. Абсолютно однакові ситуації в дзюдо практично не зустрічаються, а широка варіативність дій борців залежить від багатьох причин. Серед них основними $є$ особливості суперника в кожному конкретному поєдинку, а саме рівень майстерності, морфологічні дані, манера ведення сутички, наявність власних прийомів, турнірне становище.

Настільки широкий діапазон чинників, від яких залежить успішність зовнішньої сторони змагальної діяльності борця, зумовлює особливу важливість удосконалення механізмів адаптації та відновлення моторики спортсмена відповідно до вимог мінливої обстановки поєдинку. Така адаптація є одним із виявів спритності людини. У зв'язку з цим стає очевидним, що спритність (координаційні здібності) слід вважати провідною руховою якістю для борця.

2. Були досліджені показники та визначена динаміка координаційних здібностей юних дзюдоїстів за період експерименту. Встановлено, що на початку експерименту показники двох груп досліджуваних спортсменів були практично однакові, відмінності - недостовірні (p>0,05). За період експерименту відбулася позитивна динаміка в обох групах. Однак в експериментальній групі внутрішньо-групові показники стали достовірно вищими $(\mathrm{p}<0,05, \mathrm{p}<0,01)$, ніж у контрольній (за виключенням тесту «Стрибок у довжину 3 місця з вихідного положення обличчям вперед у напрямку руху»).

3. У процесі дослідження було розроблено та впроваджено до навчально-тренувального процесу дзюдоїстів групи спеціалізованої базової підготовки авторську методику розвитку координаційних здібностей дзюдоїстів, яка грунтується на використанні додаткових блоків спеціально підібраних акробатичних і гімнастичних вправ 3 використанням ігрового та змагального методів.

4. Під час дослідження експериментально була обгрунтована ефективність впливу методики на показники координаційних здібностей у дзюдоїстів, які займаються в ДЮСШ в групах спеціалізованої базової підготовки, що підтверджується отриманими результатами дослідження та достовірними міжгруповими відмінностями в таких показниках. Застосування розробленої методики в експериментальній групі протягом педагогічного експерименту дозволило виявити більш виражене щодо контрольної групи покращення усіх досліджуваних показників розвитку координаційних здібностей на рівні $\mathrm{p}<0,05, \mathrm{p}<0,01$.

Перспективи подальших досліджень - розробити шкалу якісної оцінки рівня розвитку координаційних здібностей, теоретично та практично обгрунтувати методику їх визначення у дзюдоїстів різних вікових груп.

\section{ЛІТЕРАТУРА}

1. Бойове самбо : навчальна програма для дитячо-юнацьких спортивних шкіл. Укл.: Велієв Є.Н., Коритний В.М., Середюк Ф.М. Республіканський науково-методичний кабінет Міністерства молоді та спорту України. К., 2017. 65 с.

2. Бойко В.Ф., Данько Г.В. Физическая подготовка борцов. Учебное пособие. К. : Олимпийская литература, 2005. $224 \mathrm{c}$.

3. Джанбырбаев Б.О. Управление учебно-тренировочным процессом квалифицированных дзюдоистов на различных етапах подготовки : автореф. дис. канд. пед. наук. Республика Казахстан : Алматы, 2010. 28 c.

4. Ерегина С.В., Тарасенко К.Н. Комплексная оценка физической подготовленности дзюдоистов. Детский тренер. 2007. № 2. С. 10-14.

5. Еганов В.А., Миронов А.О. Обоснование направленности педагогических воздействий и подбора средств тренировки при развитии координационных способностей в спортивных видах единоборств. Современные проблемы науки и образования. М., 2011. № 4. С. 18-22. 
6. Зекрин Ф.Х. Обоснованность физиологической направленности применения средств специальных тренировочных воздействий в подготовке дзюдоистов 15-18 лет. Физическая культура: воспитание, образование, тренировка. 2007. № 1. С. 74-75.

7. Лях В.И. Координационные способности: диагностика и развитие. М. : ТВТ Дивизион, 2006.290 с.

8. Мешавкин А.С. Методика обучения технико-тактическим действиям дзюдоистов на этапе начальной спортивной специализации : автореф. дис. канд. пед. наук. Тюмень, 2007. 25 с.

9. Матвеев Л.П. Теория и методика физической культуры. 4-е издание. М. : Омега-Л, 2006. 316 с.

10. Костюкевич В.М. Теорія і методика тренування спортсменів високої кваліфікації : навчальний посібник. Вінниця : «Планер», 2007. 273 с.

11. Костюкевич В.М., Шинкарук О.А., Воронова В.І., Борисова О.В. Основи науково-дослідної роботи здобувачів вищої освіти за спеціальністю Фізична культура і спорт : навч. посібник. Вид. 2-ге, без змін. К. : Олімпійська література, 2019. 528 с.

12. Скорина А.А., Врублевский Е.П. Диагностика и развитие двигательных способностей в спортивных единоборствах на этапе начальной подготовки. Вісник Чернігівського національного педагогічного університету. Серія: Педагогічні науки. Фізичне виховання та спорт. 2013. Вип. 112(1). C. 296-301.

13. Трутнев П.В. Экспериментальное обоснование повышения работоспособности дзюдоистов высокой квалификации перед соревнованиями : автореф. дис. канд. пед. наук. Красноярск, 2006. 24 с.

14. Franchini E, Del Vecchio F, Matsushique Ketal. Physiological profiles of elite judo athletes. Sports Med 2011; 41(2): 147-161.

15. Caron R.R., Coey C.A., Dhaim A.N., Schmidt R.C. Hum Mov Investigating the social behavioral dynamics and differentiation of skill in a martial arts technique. Sci. 2017 Aug;54:253-266. doi: 10.1016/j. humov.2017.05.005. Epub 2017 May 31.

\section{REFERENCES}

1. Veliyev Ye.N., Korytnyy V.M., Seredyuk F.M. (2017) Boyove sambo : Navchal'na prohrama dlya dytyacho-yunats'kykh sportyvnykh shkil [Combat Sambo: Curriculum for Children and Youth Sports Schools]. Kyiv : Respublikans'kyy naukovo-metodychnyy kabinet Ministerstva molodi ta sportu Ukrayiny (in Ukrainian).

2. Boyko V.F., Dan'ko G.V. (2005) Fizicheskaya podgotovka bortsov. Uchebnoye posobiye [Physical training of fighters]. Kyiv : Olimpiyskaya literatura. (in Russian).

3. Dzhanbyrbaev B.O. (2010) Upravlenie uchebno-trenirovochnym protsessom kvalifitsirovannykh dzyudoistov na razlichnykh etapakh podgotovki [Management of the training process of qualified judokas at various stages of training] (PhD Thesis), Almaty : Respublika Kazakhstan.

4. Eregina S.V., Tarasenko K.N. (2007) Kompleksnaya otsenka fizicheskoy podgotovlennosti dzyudoistov [Management of the training process of qualified judokas at various stages of training]. Kids coach, № 2, p. $10-14$.

5. Eganov V.A., Mironov A.O. (2011) Obosnovanie napravlennosti pedagogicheskikh vozdeystviy $i$ podbora sredstv trenirovki pri razvitii koordinatsionnykh sposobnostey v sportivnykh vidakh edinoborstv [Substantiation of the orientation of pedagogical influences and the selection of training means in the development of coordination abilities in sports types of single combats]. Modern problems of science and education, Moscow, № 4, p. 18-22.

6. Zekrin F.Kh. (2007). Obosnovannost'fiziologicheskoy napravlennosti primeneniya sredstv spetsial'nykh trenirovochnykh vozdeystviy v podgotovke dzyudoistov 15-18 let. [The substantiation of the physiological orientation of the use of means of special training influences in the training of judokas 15-18 years old]. Physical culture: upbringing, education, training, № 1, p. 74-75.

7. Lyakh V.I. (2006) Koordinatsionnye sposobnosti: diagnostika i razvitie. [Coordination abilities: diagnosis and development]. Moscow : TVT Divizion (in Russian).

8. Meshavkin A.S. (2007). Metodika obucheniya tekhniko-takticheskim deystviyam dzyudoistov na etape nachal'noy sportivnoy spetsializatsii. [Technique of teaching technical and tactical actions of judokas at the stage of initial sports specialization] (PhD Thesis). Tyumen' : Ural State Technical University.

9. Matveev L.P. (2006). Teoriya i metodika fizicheskoy kul'tury. 4-e izdanie. [Theory and methodology of physical culture. 4th edition]. Moscow : Omega-L (in Russian).

10. Kostjukevych V.M. (2007). Teorija i metodyka trenuvannja sportsmeniv vysokoji kvalifikaciji : navchaljnyj posibnyk [Theory and methodology of training athletes in the highest qualifications]. Vinnycja : "Planer" (in Ukrainian). 
11. Kostjukevych V.M., Shynkaruk O.A., Voronova V.I., Borysova O.V. (2019). Osnovy naukovo-doslidnoji roboty zdobuvachiv vyshhoji osvity za specialjnistju Fizychna kuljtura i sport : navch. Posibnyk. [Fundamentals of scientific-pre-past robots in health education for specialties Physical culture and sports : navch. google. View. 2nd, no change]. Kyiv : Olimpijsjka literature (in Ukrainian).

12. Skorina A.A., Vrublevskiy E.P. (2013). Diagnostika i razvitie dvigatel'nykh sposobnostey v sportivnykh edinoborstvakh na etape nachal'noy podgotovki. [Diagnostics and development of motor abilities in combat sports at the stage of initial training]. Bulletin of Chernihiv National Pedagogical University. Ser.: Pedagogical sciences. Physical education and sports. vol. 112, № 1, p. 296-301.

13. Trutnev P.V. (2006). Eksperimental'noe obosnovanie povysheniya rabotosposobnosti dzyudoistov vysokoy $k v a l i f i k a t s i i$ pered sorevnovaniyami. [Experimental substantiation of increasing the working capacity of highly qualified judokas before the competition] (PhD Thesis). Krasnoyarsk : Krasnoyarsk State Pedagogical University.

14. Franchini E., Del Vecchio F., Matsushique Ketal (2011). Physiological profiles of elite judo athletes. Sports Med. vol. 41, № 2, p. 147-161.

15. Caron R.R., Coey C.A., Dhaim A.N., Schmidt R.C. (2017). Hum Mov Investigating the social behavioral dynamics and differentiation of skill in a martial arts technique. Sci. 2017 Aug;54:253-266. doi: 10.1016/j. humov.2017.05.005. Epub 2017 May 31. 